\title{
Enhanced polymeric encapsulation for MEMS based multi sensors for fisheries research
}

Birkelund, Karen; Nørgaard, Lars; Thomsen, Erik Vilain

Published in:

Sensors and Actuators A: Physical

Link to article, DOI:

10.1016/j.sna.2011.06.008

Publication date:

2011

Link back to DTU Orbit

Citation $(A P A)$ :

Birkelund, K., Nørgaard, L., \& Thomsen, E. V. (2011). Enhanced polymeric encapsulation for MEMS based multi sensors for fisheries research. Sensors and Actuators A: Physical, 170(1-2), 196-201.

https://doi.org/10.1016/j.sna.2011.06.008

\section{General rights}

Copyright and moral rights for the publications made accessible in the public portal are retained by the authors and/or other copyright owners and it is a condition of accessing publications that users recognise and abide by the legal requirements associated with these rights.

- Users may download and print one copy of any publication from the public portal for the purpose of private study or research.

- You may not further distribute the material or use it for any profit-making activity or commercial gain

- You may freely distribute the URL identifying the publication in the public portal

If you believe that this document breaches copyright please contact us providing details, and we will remove access to the work immediately and investigate your claim. 


\title{
Enhanced polymeric encapsulation for MEMS based multi sensors for fisheries research
}

\author{
Karen Birkelund*, Lars Nørgaard, Erik V. Thomsen \\ Technical University of Denmark, Department of Micro and Nanotechnology, Ørsted Plads, Building 345 East, 2800 Kgs. Lyngby, Denmark
}

\section{A R T I C L E I N F O}

\section{Article history:}

Received 19 October 2010

Received in revised form 6 June 2011

Accepted 6 June 2011

Available online $\mathrm{xxx}$

\section{Keywords:}

Encapsulation

Packaging

Harsh environment

Silanisation

MEMS

Data storage tag

Fisheries research

Oceanic environment

\begin{abstract}
A B S T R A C T
This paper presents the challenges of a packaged MEMS-based multi sensor system that allow for direct exposure of the sensing part to sea water. The system is part of a data storage tag used on fish to provide the researcher with information on fish behaviour and migration. The sensor measures light intensity, temperature, pressure and conductivity. For precise and fast measurements a direct exposure of the sensor to the water is desirable. A potted tube encapsulation concept has shown to be promising for accurate and fast measurements in harsh environment, provided a tight sealing of the electronics can be made. In this paper we investigate the interfacial delamination of an epoxy encapsulated chip. Differently prepared silicon chips are investigated and it is found that silicon dioxide surfaces functionalised with (3-aminopropyl) triethoxysilane will improve this encapsulation approach compared to low pressure chemical vapor deposited (LPCVD) silicon nitride and untreated silicon dioxide.
\end{abstract}

(c) 2011 Elsevier B.V. All rights reserved.

\section{Introduction}

More and more applications require very accurate MEMS-based sensors that can measure various parameters with high sensitivity and with a fast response time. This can be achieved by having a direct contact between the sensor that measures and the media to measure on, such that the measured signal does not have to be transferred through a bulky encapsulation, with a delay and loss in signal strength as a consequence. Often the media is very harsh for MEMS-based sensors and that puts certain constraints and challenges to the encapsulation scheme and the choice of materials for the sensor itself. This applies for instance for various body sensors and pressure sensors. Duun et al. [1] have reported on an electronic patch measuring pulse oximetry, where a direct contact to the human skin is required while electronics and batteries are protected against sweat and moisture. Numerous examples on pressure sensors encapsulated to withstand various harsh environments like district heating water [2] or oceanic environment [3] can be found in the literature which in common require a direct exposure while protecting more vital elements like electronics.

\footnotetext{
* Corresponding author. Tel.: +45 45255700; fax: +45 45887762.

E-mail address: Karen.Birkelund@nanotech.dtu.dk (K. Birkelund).
}

We have developed an encapsulation concept for a MEMS based multi sensor for fisheries research that also apply for a direct contact to saltwater. The sensor chip itself consist of four integrated sensors: conductivity sensor, pressure sensor, temperature sensor and light sensor. The four sensors gives together information about the salinity of the water, depth, temperature, day and night together with information about longitude and latitude. The performance of the four sensors is described and analysed in details elsewhere [4-7].

The chip is a part of a data storage tag (DST), a system that consists of a micro controller that activates the sensors and stores measured data. The system is powered by batteries. The DST is aimed to be placed on fish and when the fish are re-caught the data is read out either by physical contacts in the DST or by powering the system through a wireless interface. The data can then be used to estimate the fish migration route by geo-location [8-10].

To achieve the direct exposure of the sensors a potting tube concept has been chosen. Batteries and PCB with electronics and sensor chip is placed in a polystyrene tube which is subsequently filled with a polymer. This seal off all but the sensing part that will stick out in one end of the package. This packaging concept has previous been published in [6]. In this paper we evaluate the stability of the encapsulation scheme and propose a functionalisation step to enhance the stability of the encapsulation. The use of silane coupling agents for enhanced adhesion is widely used in the 
(a)

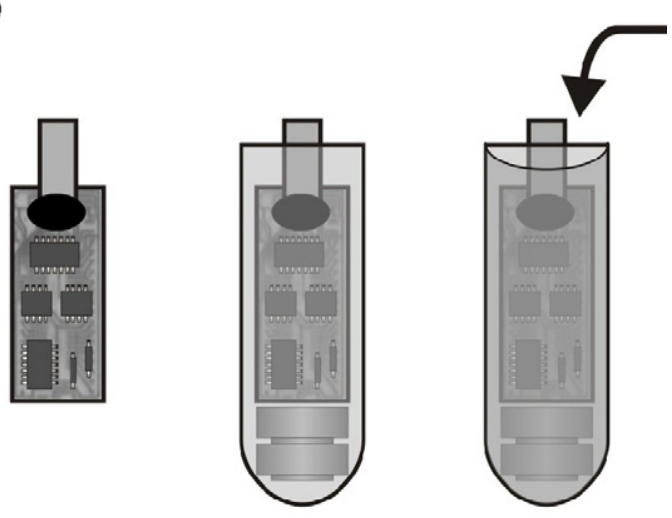

(b)

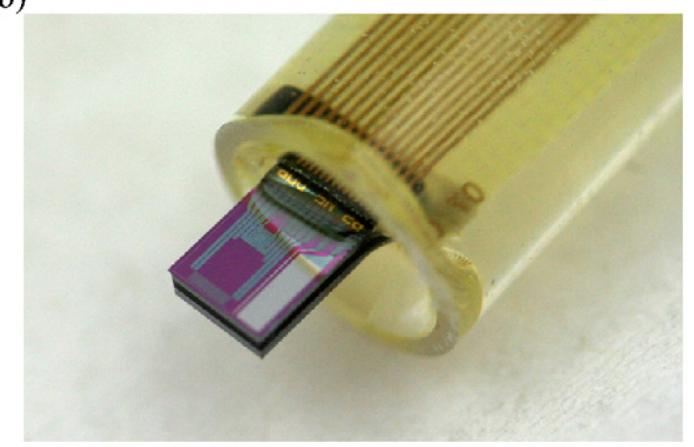

Fig. 1. (a) Packaging scheme of the multi-sensor. PCB with sensor and electronics are placed together with batteries in a tube which is filled with epoxy leaving the end of the sensor chip exposed in one end. (b) A potted multi-sensor (without electronics and batteries). On the back side thermistor and yet a pair of conductivity electrodes are present.

microelectronic industry either as functionalised surfaces, or as additives in epoxies [11-16].

\section{Multi sensor chip and encapsulation}

The sensor chip is fabricated by conventional bulk micro machining and is reported elsewhere [7]. The miniaturized multi sensor consists of two separate chips. One containing a pressure sensor and a light sensor. The other chip contains the temperature sensor. Each chip further contains a pair of conductivity electrodes made of platinum. The sensing part exposed to the sea water has to be protected without disturbing the functionality. This is done using titanium di-silicide interconnections covered with silicon nitride as protective coating. Stoichiometric low pressure chemical vapor deposited (LPCVD) silicon nitride $\left(\mathrm{Si}_{3} \mathrm{~N}_{4}\right)$ is a conformal coating which is known to be a very efficient diffusion barrier due to a very low diffusivity of water. The diffusion coefficient $D$ of water through a plasma enhanced chemical vapor deposited PECVD $\mathrm{Si}_{3} \mathrm{~N}_{4}$ film is $10^{-18} \mathrm{~cm}^{2} / \mathrm{s}$ according to [17]. Using the approximate diffusion length $l=\sqrt{D t}$ gives a diffusion time $t$ for water to diffuse through a nitride film of thickness $l=100 \mathrm{~nm}$ of more than 3 years. In our design we use a stoichiometric LPCVD nitride which has an even lower diffusivity.

The two chips are assembled by anodic bonding to opposing sides of a pyrex wafer. The bonding also seals the reference cavity of the pressure sensor. The complete triple stack multi-sensor is $3.9 \mathrm{~mm} \times 7.3 \mathrm{~mm} \times 1.2 \mathrm{~mm}$.

The chip is flip chip mounted to a PCB substrate and wire bonds are connecting the sensors on the other side the chip. The wires are glob topped. Finally the substrate is placed in a polystyrene tube and potted with an epoxy as illustrated in Fig. 1.

\section{Packaging considerations}

Experience from the Baltic sea with cods tagged with commercial available DST have showed that $40 \%$ of all tags are recaptured within 1 year. Since the tags usually measure for 2 years due to battery capacity the encapsulation of the sensor presented in this article are specified to last for minimum 2 years.

When encapsulating the multi sensor chip several conditions have to be made when selecting the right encapsulation materials and method. First of all it is essential that the temperature does not exceed $70^{\circ} \mathrm{C}$ during the encapsulation process, otherwise the batteries included in the package will be damaged. Secondly, the water absorption of the material should be low to avoid salt water to penetrate the encapsulation and corrode the electrical connections. Further, good adhesion between the sensor chip that is sticking out of the package and the package material has to be obtained to avoid penetration of salt water along the interface of the chip. Such an indiffusion of water usually break the bonds between the encapsulation material and the chip surface and a leakage will appear. The potting material should besides exhibit a high chemical stability and be electrical insulating and viscosity should be low to ease the potting process. Also the ionic impurity of the potting material should be low to avoid corrosion of the metal contacts.

The sensor is specified to operate at pressures ranging from $1 \mathrm{bar}$ to 30 bars and at temperatures ranging from $-2{ }^{\circ} \mathrm{C}$ to $25^{\circ} \mathrm{C}$, but the packages must withstand temperatures down to $-20^{\circ} \mathrm{C}$, because when the fish is caught it is cooled down.

Finally, the tag must not disturb the behaviour of the fish, the tag should have a neutral colour, not making the fish more visible than usual, have a zero buoyancy mass and be as small as possible. A tag measuring $17 \mathrm{~mm}$ in width and $46 \mathrm{~mm}$ in length is suitable for cods while it has to be miniaturized for smaller fish.

Three epoxies have been chosen for investigation for the potting process. The epoxies are listed in Table 1 . They all have a specific weight of $1.1 \mathrm{~g} \mathrm{~cm}^{-3}$, good electrical insulation properties and the glass transition temperature $T_{\mathrm{g}}$ is well above the working temperature. Further, they are all transparent and have a relatively low viscosity, which ease the potting process. Finally they can all be cured at room temperature. Most epoxies have a curing schedule higher than $80^{\circ} \mathrm{C}$ and exhibits further exothermic heating.

In general epoxies are known to have a low water absorption (normally listed to be $<1 \%$ ). However, it is difficult to compare the data from the supplier data sheets because they are often not measured under same conditions and seldom to the saturation point. Therefore, we have measured the water uptake until saturation and estimated the diffusion coefficient for each of the three epoxies as reported earlier in [6]. The estimated diffusion coefficients for the three epoxies cured at room temperature are further listed in Table 1.

Epotek 305 has the highest water uptake of the three and has been chosen as a reference only. Due to the high water uptake and a low $T_{\mathrm{g}}$ it is not a good choice for the packaging. Epotek $302-3 \mathrm{M}$ is a good option due to the low water uptake and Epotek 301-2FL is good due to the low viscosity. The best choice would be a polymer with a high diffusion constant so saturation point is reached fast together with a low total water uptake. As a compromise we have chosen to use Epotek 302-3M due to the lowest water uptake.

For fixation of the chip during the potting process a $30 \mathrm{~mm}$ long polystyrene tube is chosen with a wall thickness of $1 \mathrm{~mm}$ and inner diameter of $8 \mathrm{~mm}$. The smallest distance into the vital parts through the tube is through $2 \mathrm{~mm}$ epoxy and $1 \mathrm{~mm}$ polystyrene. Assuming that the polystyrene has approximately same diffusion coefficient as the Epotek 302-3M gives a diffusion time of the water through the package of 1.9 years. For longer diffusion times glass tubes or metal tubes with very low diffusion constants would be a good choice. 
Table 1

Key parameters for three epoxies cured at room temperature. Epotek 302-3M has the lowest water uptake while 305 has the highest.

\begin{tabular}{|c|c|c|c|c|}
\hline \multirow[t]{2}{*}{ Epoxy name } & \multicolumn{2}{|l|}{ Suppliers values } & \multicolumn{2}{|l|}{ Measured values } \\
\hline & Viscosity (cPs) & $T_{\mathrm{g}}\left({ }^{\circ} \mathrm{C}\right)$ & Water uptake (wt.\%) & Diffusion constant $\left(10^{-9} \mathrm{~cm}^{2} / \mathrm{s}\right)$ \\
\hline Epotek 302-3M & $800-1600$ & 65 & 3.2 & $1.5 \pm 0.2$ \\
\hline Epotek 301-2FL & 125 & 60 & 4.1 & $6.5 \pm 0.2$ \\
\hline Epotek 305 & $100-300$ & 30 & 14.4 & $10.7 \pm 2.7$ \\
\hline
\end{tabular}

\section{Packaging failure}

Long term tests of such encapsulated chips have revealed that water penetrate along the epoxy/sensor interface. This is presumably caused by environmentally induced delamination [18], why improvement of the adhesion strength between the sensor surface and the epoxy is required. With the described encapsulation scheme a meniscus will form between the epoxy and the chip surface which make reproducible reliability test difficult. To do systematic reliability test a mould was therefore made to ensure an planar encapsulation front normal to the chip surface.

The mould consists of two similar aluminum shells, each with a half cylindric hollowing, and in the closed end of the cylinder a gasket is made of silicone rubber to ensure the absence of epoxy on the chip surface that is sticking out. The dimensions of the mould when assembled are $15 \mathrm{~mm}$ in diameter and $15 \mathrm{~mm}$ in depth. The mould is coated prior to epoxy potting, with a slip agent based on PTFE to ensure easy release of the encapsulated chip after curing. The epoxy is mixed according to the datasheet, degassed in an exicator, poured into the mould where the chip has been placed with high accuracy. The mould is placed in an oven and cured at $65^{\circ} \mathrm{C}$ for $2 \mathrm{~h}$. By curing the epoxy at elevated temperatures the diffusivity decreases due to a higher curing extension [19]. The diffusivity of Epotek $302-3 \mathrm{M}$ cured at $65^{\circ} \mathrm{C}$ has in this work been measured for three different temperatures when immersed in $3.5 \%$ potassium chloride solution, and the values are listed in Table 2.

After releasing the encapsulated chips from the mould the samples are grind and polished to achieve a transparent surface in order to be able to observe the delamination optically. After grinding and polishing the total thickness measures $10 \mathrm{~mm}$. The dimensions are deliberately made large to ensure that the overall diffusion times of the salt water through the encapsulation is much longer than the diffusion time from the encapsulation front. The time it will take the water to reach the sample by diffusing $4.5 \mathrm{~mm}$ through the encapsulation from the grind surface are listed in Table 2 for three different temperatures.

The encapsulation depth is evaluated by use of triangles fabricated in metal along the edges of the chip. The apexes have a spacing of $200 \mu \mathrm{m}$. The vertical and angular position of the encapsulation front is determined by pixel counting with an uncertainty of less than $10 \mu \mathrm{m}$. The chips have been placed with a accuracy less than $\pm 90 \mu \mathrm{m}$ from the intended position and the angular deviation is less than $3.4^{\circ}$. The encapsulation front is seen to be very well defined and is shown in Fig. 2.

Table 2

Measured diffusion constants for Epotek 302-3M when immersed into 3.5\% potassium chloride solution at three different temperatures and calculated diffusion times through $2.0 \mathrm{~mm}$ and $4.5 \mathrm{~mm}$ encapsulant.

\begin{tabular}{llll}
\hline \multirow{2}{*}{$\begin{array}{l}\text { Temperature } \\
\left({ }^{\circ} \mathrm{C}\right)\end{array}$} & $\begin{array}{l}\text { Measured diffusion } \\
\text { constant }\left(\mathrm{cm}^{2} / \mathrm{s}\right)\end{array}$ & \multicolumn{2}{l}{ Diffusion time through } \\
\cline { 3 - 4 } & & $2.0 \mathrm{~mm}$ (years) & $4.5 \mathrm{~mm}$ (years) \\
\hline 10 & $0.19 \times 10^{-9}$ & 6.7 & 33.8 \\
22 & $0.52 \times 10^{-9}$ & 2.4 & 12.4 \\
50 & $7.10 \times 10^{-9}$ & 0.2 & 0.9 \\
\hline
\end{tabular}

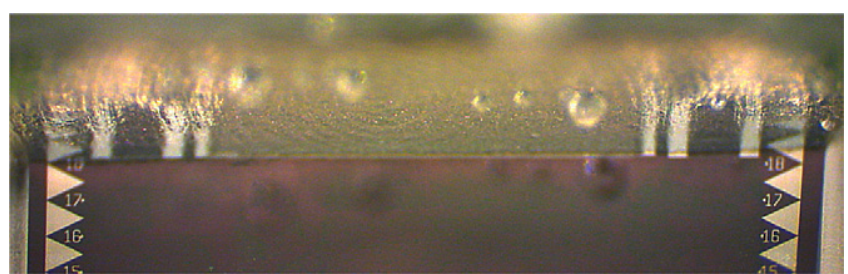

Fig. 2. A close up view of an encapsulated test chip with the encapsulating polymer at the top. The encapsulation front is well defined. The apexes of the triangles along the chip edges have a spacing of $200 \mu \mathrm{m}$ and the chip is $4 \mathrm{~mm}$ wide.

\section{Delamination test}

Different chip surfaces are prepared to test delamination profiles caused by water penetration: Stoichiometric LPCVD silicon nitride, LPCVD TEOS, thermally grown silicon dioxide and thermally grown silicon dioxide functionalised with (3-aminopropyl) triethoxysilane. The functionalisation procedure of silane molecules to silicon nitride surfaces is well described in the literature and does normally involve wet chemical cleaning and oxidation by RCA1 $\left(5 \mathrm{H}_{2} \mathrm{O}: 1 \mathrm{H}_{2} \mathrm{O}_{2}: 1 \mathrm{NH}_{4} \mathrm{OH}\right)$ and $10 \%$ nitric acid $\left(\mathrm{HNO}_{3}\right)$ solutions $[20,21] . \mathrm{HNO}_{3}$ is used to prepare the surface with hydroxyl groups that the (3-aminopropyl) triethoxysilane can form covalent bonds with. However, these treatments are incompatible with processed chips having metal contacts. It was therefore investigated if other treatments could be used. The samples were exposed to either RCA1 cleaning, plasma cleaning or UV-ozone treatment.

The different cleaning procedures have been investigated and analysed with contact angle measurements using benzyl alcohol. The result of the contact angle measurements are shown in Fig. 3. The treated surfaces have a similar decrease in contact angle of around $13^{\circ}$ to the untreated surfaces. Each data point is the average for 3 samples, and the error bars indicate the maximal deviation which is between $0.4^{\circ}$ and $2.4^{\circ}$. The difference in contact angle between the differently treated surfaces are less than $1.6^{\circ}$, which is within the uncertainty of the measurements. The decrease in contact angle indicates that the surfaces have become more hydrophilic due to the formation of hydroxyl groups. Since the UV-ozone treatment it not found inferior to the RCA1 and the plasma treatment,

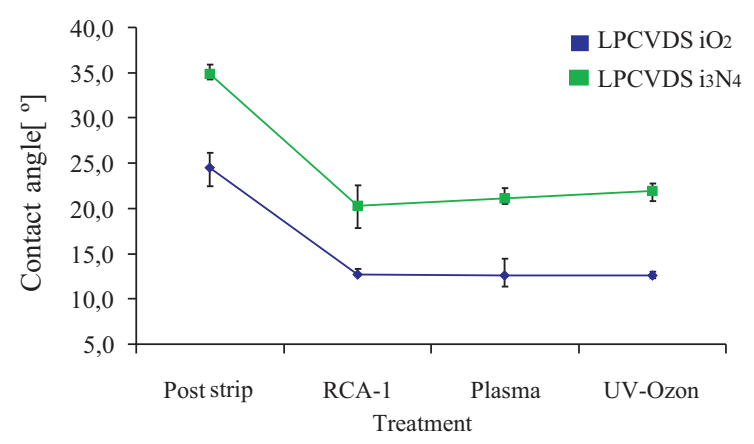

Fig. 3. The contact angle of benzyl alcohol to silicon nitride and silicon dioxide. The contact angle drops with around $13^{\circ}$, when the surface has been exposed to a cleaning/activation treatment. Each data point is the average for 3 samples, and the error bars indicate the maximal deviation. 


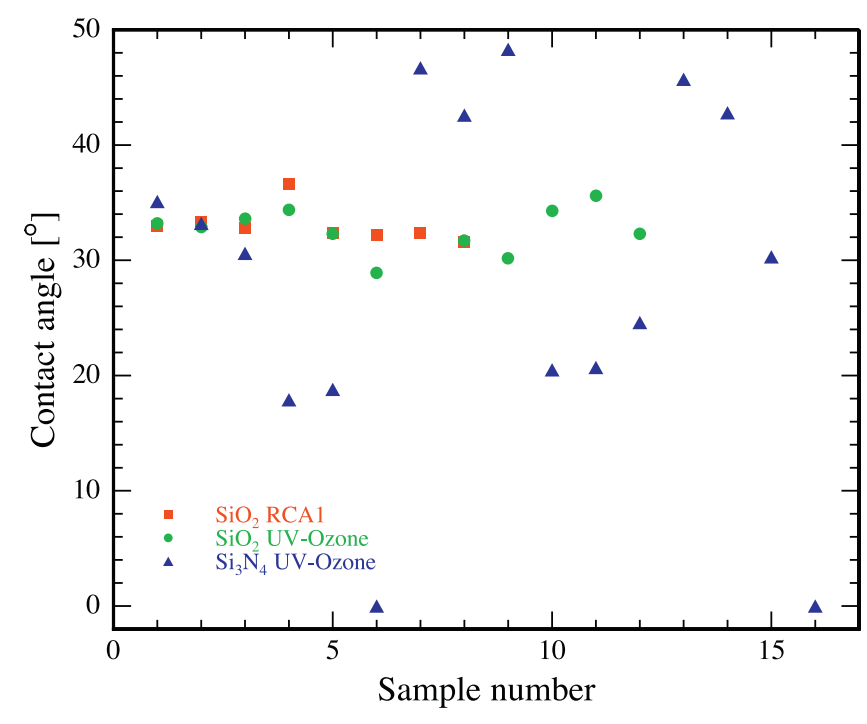

Fig. 4. The contact angle of benzyl alcohol to functionalised silicon nitride and silicon dioxide. The RCA cleaned $\mathrm{SiO}_{2}$ and UV-ozone treated $\mathrm{SiO}_{2}$ shows similar stable contact angle measurements while the measured contact angles for nitride are fluctuating.

UV-ozone cleaning is used prior to functionlisation and encapsulation. A thorough analysis of the cleaning performance of UV-ozone and plasma treatments are given in [22-24].

Directly after the UV-ozone treatment the chips are functionalised by a $3 \mathrm{~h}$ incubation in a mixture consisting of IPA: $\mathrm{H}_{2} \mathrm{O}$ :amino silane (40:1:1) followed by a $3 \mathrm{~h}$ long IPA dip. Finally the chips are stored in an exicator until use.

The functionalised surfaces have also been analysed by contact angle measurements using benzyl alcohol to verify the success of the functionalisation procedure. The results are shown in Fig. 4. It is seen that the $\mathrm{SiO}_{2}$ surfaces show similar stable contact angle measurements while that for $\mathrm{Si}_{3} \mathrm{~N}_{4}$ surfaces are fluctuating (Fig. 3). This observation together with the lower measured contact angle shown in Fig. 3 indicates that for the $\mathrm{SiO}_{2}$ surfaces a stable and uniform formation of hydroxyl groups has been formed allowing a reproducible functionalised surface, whereas this is not the case for the $\mathrm{Si}_{3} \mathrm{~N}_{4}$. However, in order to make conclusions about the exact molecular formation on the surfaces after the cleaning/activation treatment more efficient investigation methods like, e.g. XPS has to be performed.

Due to the contact angle measurements only the $\mathrm{SiO}_{2}$ surfaces are functionalised in the following delamination tests, while the other samples are encapsulated directly after the UV-treatment. Hence, 4 UV-treated $\mathrm{Si}_{3} \mathrm{~N}_{4}$ chips, 2 UV-treated $\mathrm{SiO}_{2}$ and $2 \mathrm{SiO}_{2}$ chips that are UV-treated and functionalised are encapsulated for delamination test when immersed into water. The encapsulated samples are submerged into a beaker with a $3.5 \%$ potassium chloride solution at $50^{\circ} \mathrm{C}$. The high temperature was chosen in order to speed up the process. Also pressures up to 10 bars were applied, however, it has not been possible to detect any accelerated effect caused by the pressure. Regular inspection of the samples were made for 48 days, but the samples were kept in the saltwater for 83 days in total.

Scanning electron microscope (SEM) images has been taken of the $\mathrm{Si}_{3} \mathrm{~N}_{4}$ chip/polymer interface before and after immersion in water and shown in Fig. 5. It is clear from Fig. 5(a) that before immersion into water the chip surface is completely wetted by the epoxy while after immersion into water for 83 days the epoxy has de-attached from the surface and reveals a gap. Shown in Fig. 5(b).

The development of the environmental induced delamination along the $\mathrm{Si}_{3} \mathrm{~N}_{4}$ sample is shown in Fig. 6 and the delamination lengths are listed in Table 3. For comparison the calculated diffu- (a)

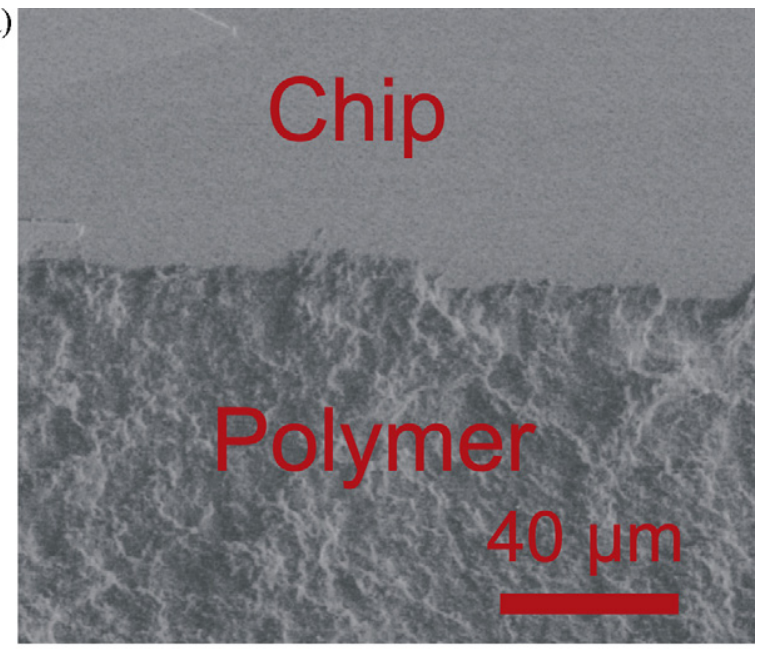

(b)

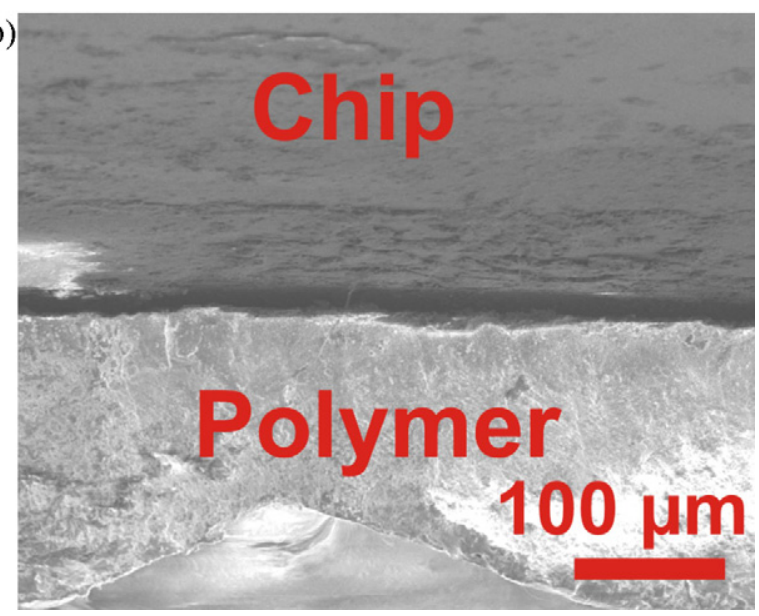

Fig. 5. SEM images of the chip/epoxy interface. (a) Before immersion into water. The epoxy has fully wetted the chip surface. (b) After immersion into water. The epoxy has delaminated from the chip surface.

sion lengths using the approximation $l=\sqrt{D t}$ and the measured diffusion constant for Epotek $302-3 \mathrm{M}$ at $50^{\circ} \mathrm{C}$ are also listed in the table.

The encapsulation front is in top of Fig. 6(a) and the delamination front at different times is marked with a white curve. As the delamination front progresses the profile turns from planar to concave. The measured delamination length as it progress with time is plotted for the 3 samples with different surfaces in Fig. 7. For comparison with diffusion of saltwater through the encapsulant the diffusion length as a function of time is also plotted using the approximation $l=\sqrt{D t}$ and the measured diffusion constant for Epotek $302-3 \mathrm{M}$ at $50^{\circ} \mathrm{C}$.

For the nitride and oxide samples the delamination is described by a 3-stage behaviour: an initial hesitation after immersion in water followed by an rapid delamination and finally a linear progressing. For the nitride sample the initial hesitation is

Table 3

The developed delamination length with time for an encapsulated nitride chip immersed in $50^{\circ}$ saltwater, and the calculated diffusion length through the encapsulant.

\begin{tabular}{ccc}
\hline Time $(\mathrm{h})$ & Delamination length $(\mu \mathrm{m})$ & Diffusion length $(\mu \mathrm{m})$ \\
\hline 12 & 875 & 175 \\
54 & 1475 & 371 \\
313 & 1975 & 894 \\
573 & 2175 & 1210 \\
\hline
\end{tabular}


(a)

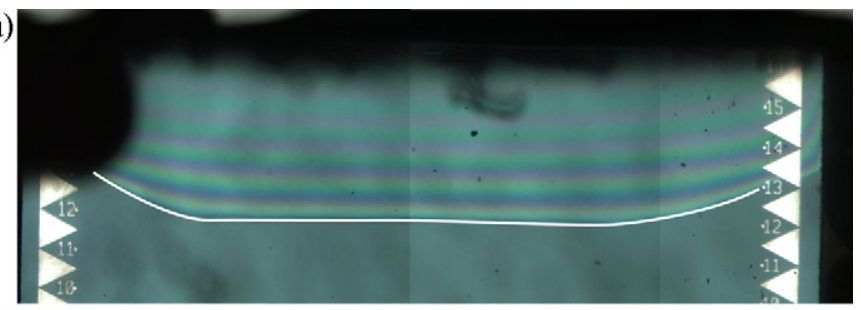

(b)

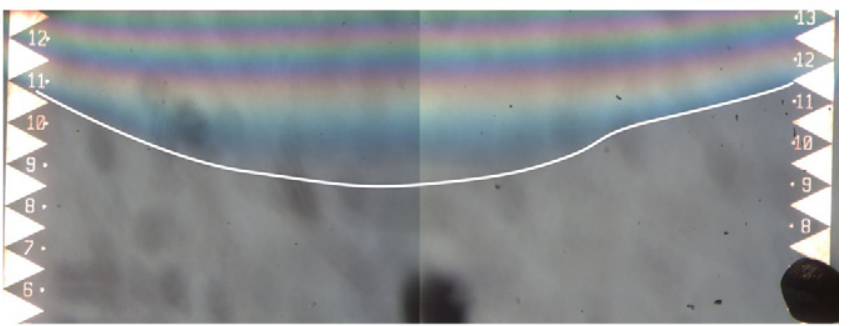

(c)

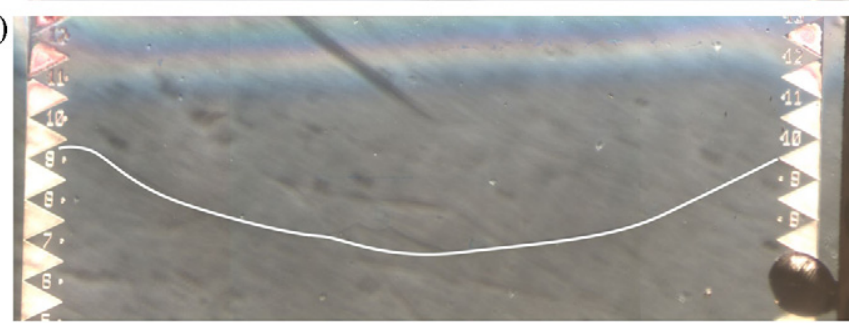

(d)

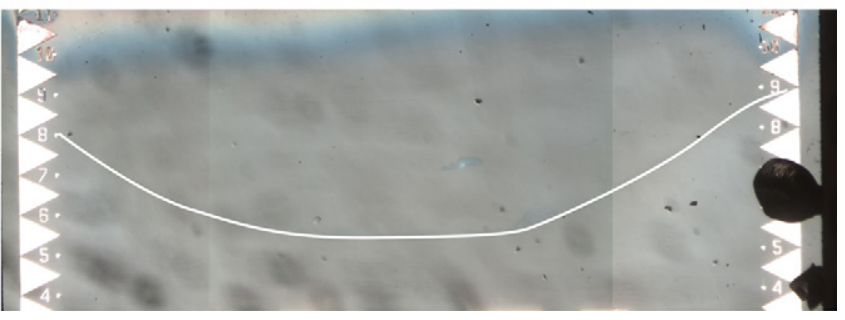

Fig. 6. The front side interface of the silicon nitride sample at different times. The position of the delamination front is marked with a white curve, and the shape of the curve turns from planar to concave. The spacing between the apexes of the triangles is $200 \mu \mathrm{m}$ and the immersion time and delamination lengths for the different images are: (a) time: $12 \mathrm{~h}$, length: $875 \mu \mathrm{m}$; (b) time: $54 \mathrm{~h}$, length: $1475 \mu \mathrm{m}$; (c) time: $313 \mathrm{~h}$, length: $1975 \mu \mathrm{m}$; and (d) time: $573 \mathrm{~h}$, length: $2175 \mu \mathrm{m}$.

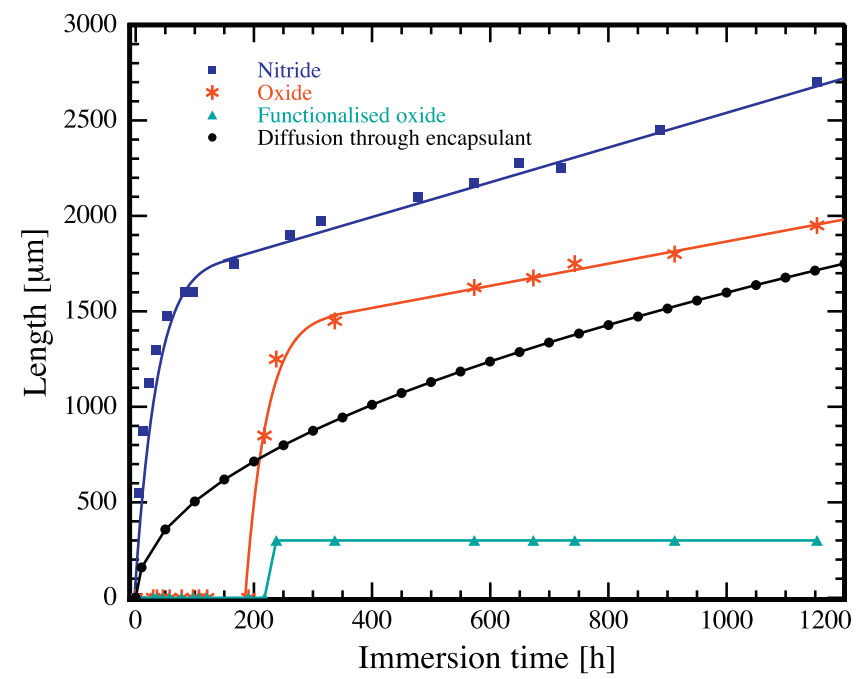

Fig. 7. The delamination profiles for an encapsulated nitride sample, oxide sample and functionalised oxide sample. A trend line is included as a guide for the eye. For comparison the diffusion length of salt water through the encapsulant as a function of time is also plotted.
$3 \mathrm{~h}$ and the fast delamination occur between $3 \mathrm{~h}$ and $55 \mathrm{~h}$ after immersion whereafter the delamination progresses with a rate of $0.98 \mu \mathrm{m} / \mathrm{h}$. For the oxide samples the hesitation time is prolonged to $191 \mathrm{~h}$ followed by a fast non-linear delamination and after $337 \mathrm{~h}$ the delamination becomes linear progressing with a speed of $0.58 \mu \mathrm{m} / \mathrm{h}$. For the functionalised samples a $300 \mu \mathrm{m}$ delamination were observed after 10 days and no further delamination was observed the following 73 days where the experiment was ended. It is seen that in the case of the nitride and the oxide sample the water penetrates along the interface considerably faster than can be explained alone by diffusion through the encapsulant.

The presence of the hesitation before delamination is ascribed to a weakening of the interface by a dissociation of the weak interfacial bonds taking place before the delamination can initiate. When the delamination initiate the stress built up in the epoxy causes the fast non-linear delamination. The stress itself, is presumably caused by the curing shrinkage of the epoxy, while its position dependency is caused by the shape of the encapsulation, which creates a large local shear force at the encapsulation front. To postpone or eliminate the environmental induces delamination other stress inducing factors like the encapsulation shape, casting and curing procedure should be addressed.

Considering a DST chip encapsulated in a potted tube packaging scheme as proposed in the beginning of this paper, with an incorporated safety margin of $2 \mathrm{~mm}$ from the encapsulation front to the vital parts like wire bonds and flip chip connections, implies that using an untreated $\mathrm{Si}_{3} \mathrm{~N}_{4}$ coated surface the water will reach the vital parts within 20 days when immersed in $50^{\circ} \mathrm{C}$ salt water. Interfacial degradation of epoxy coated LPCVD $\mathrm{Si}_{3} \mathrm{~N}_{4}$ when exposed to condensed water has previous been reported [25]. In the case of $\mathrm{SiO}_{2}$ the package will survive for about 51 days while the functionalised $\mathrm{SiO}_{2}$ samples survive for at least 83 days. The time for saltwater to diffuse through $2 \mathrm{~mm}$ encapsulation will be 65 days at $50{ }^{\circ} \mathrm{C}$. All other distances into the vital parts will be larger and thereby have longer diffusion times. Since cods in the Baltic sea primarily lives in water with temperatures ranging from $-2{ }^{\circ} \mathrm{C}$ to $20^{\circ} \mathrm{C}$ the diffusion times will decrease considerable. Hence, for $10^{\circ} \mathrm{C}$ warm saltwater it will take more than 6 years to diffuse through $2 \mathrm{~mm}$ of the encapsulant. It is difficult to convert the numbers for delamination into real systems exposed to ocean water with temperatures ranging from $-2{ }^{\circ} \mathrm{C}$ to $25^{\circ} \mathrm{C}$ because of minor knowledge to the activation energy of the interfacial bonds. However, these results means that the first step for achieving higher stability of the packaging solution for the DST with directly exposed sensors is to make a fabrication process where the surface is terminated with an oxide instead of LPCVD $\mathrm{Si}_{3} \mathrm{~N}_{4}$. Silicon nitride is, however, a desired candidate due to a very low diffusivity of water and should be preserved beneath the silicon oxide.

\section{Conclusion}

We have presented an encapsulation approach for a MEMSbased multi sensor system that allow for a direct exposure of sea water to the sensing part. The weak part of the packaging is the interface between chip and encapsulant which in this case is an epoxy. Differently prepared chip surfaces have been investigated and it has been demonstrated that the functionalised silicon dioxide surface has a better resistance against an environmental induced delamination than a non-functionalised $\mathrm{Si}_{3} \mathrm{~N}_{4}$ and $\mathrm{SiO}_{2}$ surface. So the first step for achieving higher stability of the packaging solution for the DST with directly exposed sensors is to make a fabrication process where the surface is terminated with an oxide. This is an essential conclusion that apply for all epoxy encapsulated sensor systems with sensors directly exposed to harsh environments. 


\section{References}

[1] S. Duun, R.G. Haahr, O. Hansen, K. Birkelund, E.V. Thomsen, High quantum efficiency annular backside silicon photodiodes for reflectance pulse oximetry in wearable wireless body sensors, Journal of Micromechanics and Microengineering 20 (7) (2010), Article Number: 075020.

[2] C. Pedersen, S.T. Jespersen, K.W. Jacobsen, J.P. Krog, C. Christensen, E.V. Thomsen, Highly reliable O-ring packaging concept for MEMS pressure sensors, Sensors and Actuators A 115 (2004) 617-627.

[3] A. Mohan, A.P. Malshe, S. Aravamudhan, S. Bhansali, Piezoresistive MEMS pressure sensor and packaging for harsh oceanic environment, in: 54th Electronic Components and Technology Conference, IEEE, vol. 1, 2004, pp. 948-950.

[4] A. Hyldgård, O. Hansen, E.V. Thomsen, Fish \& chips: single chip silicon MEMS CTDL salinity, temperature, pressure and light sensor for use in fisheries research, in: IEEE MEMS 2005 Proceedings, 2005, pp. 303-306.

[5] A. Hyldgård, Í. Olafsdóttir, M. Olesen, T. Hedegaard, O. Hansen, E.V. Thomsen, Fish \& chips: four electrode conductivity/salinity sensor on a silicon multisensor chip for fisheries research, in: IEEE Sensors 2005 Proceedings, 2005, pp. 1124-1127.

[6] A. Hyldgård, K. Birkelund, J. Janting, E.V. Thomsen, Direct media exposure of MEMS multi-sensor systems using a potted-tube packaging concept, Sensors and Actuators A: Physical 142 (1) (2008) 398-404.

[7] A. Hyldgård, D. Mortensen, K. Birkelund, O. Hansen, E.V. Thomsen, Autonomous multi-sensor micro-system for measurement of ocean water salinity, Sensors and Actuators A: Physical 147 (2) (2008) 474-484.

[8] S. Neuenfeldt, H. Hinrichsen, A. Nielsen, K.H. Andersen, Reconstructing migrations of individual cod (Gadus morhua L.) in the Baltic Sea by using electronic data storage tags, Fisheries Oceanography 16 (6) (2007) 526-535.

[9] K.H. Andersen, A. Nielsen, U.H. Thygesen, H. Hinrichsen, S. Neuenfeldt, Using the particle filter to geolocate Atlantic cod (Gadus morhua) in the Baltic Sea, with special emphasis on determining uncertainty, Canadian Journal of Fisheries and Aquatic Sciences 64 (4) (2007) 618-627.

[10] M.W. Pedersen, D. Righton, U.H. Thygesen, K.H. Andersen, H. Madsen, Geolocation of North Sea cod (Gadus morhua) using hidden Markov models and behavioural switching, Canadian Journal of Fisheries and Aquatic Sciences 65 (11) (2008) 2367-2377.

[11] Q. Tong, B. Ma, A. Xiao, A. Savoca, C.P. Shijian Luo, Wong, Fundamental adhesion issues for advanced flip chip packaging, in: 52nd Electronic Components and Technology Conference 2002, 2002, pp. 1373-1379.

[12] S.J. Luo, C.P. Wong, Investigation on effect of coupling agents in epoxy based underfill material for flip chip application, in: Proceedings of 50th Electronic Components \& Technology Conference (ECTC 01), 2000, pp. 311-318.

[13] S.J. Luo, C.P. Wong, Study on effect of coupling agents on underfill material in flip chip packaging, in: International Symposium and Exhibition on Advanced Packaging Materials, vol. 24(1), 2001, pp. 38-42.

[14] M.B. Vincent, L. Meyers, C.P. Wong, Enhancement of underfill adhesion to die and substrate by use of silane additives, in: International Symposium on Advanced Packaging Materials, 1998, pp. 49-52.

[15] F.T. Tan, X.L. Qiao, J.G. Chen, H.S. Wang, Effects of coupling agents on the properties of epoxy-based electrically conductive adhesives, International Journal of Adhesion \& Adhesives 26 (2006) 406-413.

[16] D.I. Tee, M. Mariatti, A. Azizan, C.H. See, K.F. Chong, Effect of silane-based coupling agent on the properties of silver nanoparticles filled epoxy composites, Composites Science and Technology 67 (2007) 2584-2591.

[17] R.K. Ulrich, A.J. Phillips, D.H. Yi, W.D. Brown, S.S. Ang, Mechanical stability of PECVD silicon nitride protective films over bondwires, bonds and bond- pads during thermal stress, Microelectronics and Reliability 31 (1991) 1237 1249.

[18] M.W. Lane, J.M. Snodgrass, R.H. Dauskardt, Environmental effects on interfacial adhesion, Microelectronics and Reliability 41 (9-10) (2001) 1615-1624.

[19] H.E. Bair, Curing behavior of an epoxy-resin above and below $T_{g}$, Abstracts of Papers of the American Chemical Society 189(April) (1985) 24.

[20] A. Holtzman, S. Richter, Electroless plating of silicon nitride using (3aminopropyl) triethoxysilane, Journal of the Electrochemical Society 155 (3) (2008) D196-D202.

[21] Z.Q. Wei, C. Wang, C.F. Zhu, C.Q. Zhou, B. Xu, C.L. Bai, Study on singlebond interaction between amino-terminated organosilane self-assembled monolayers by atomic force microscopy, Surface Science 459 (3) (2000) 401-412.

[22] R. Stine, C.L. Cole, K.M. Ainslie, S.P. Mulvaney, L.J. Whitman, Formation of primary amines on silicon nitride surfaces: a direct, plasmabased pathway to functionalization, Langmuir 23 (8) (2007) 4400-4404.

[23] M.-L. Sham, M. Lam, J.-K. Kim, Adhesion characteristics of underfill material with various package components after plasma and uv/ozone treatments, in: Advances in Electronic Materials and Packaging 2001 (Cat. No.01EX506), 2001, pp. 208-215.

[24] M. Teo, K.Y. Lee, A. Chew, S. Lim, C. Lee, M. Nonomura, Plasma surface modification and impact on msl performance for flip chip packaging, in: 2007 9th Electronics Packaging Technology Conference, 2007, pp. 657-663.

[25] J. Park, D.G. Harlow, Interfacial degradation of epoxy coated silicon nitride, IEEE Transactions on Components and Packaging Technologies 25 (3) (2002) 470-477.

\section{Biographies}

Karen Birkelund received her M.Sc. degree from Roskilde University Center, Denmark in 1993 and her Ph.D. degree in electrical engineering in 1997 from the Technical University of Denmark (DTU). From 1998 to 2002 she was at Danfoss A/S as research engineer within MEMS pressure sensors. From 2002 to 2004 she was at Cantion A/S as research engineer within cantilever based sensor systems. From 2004 to 2006 she was with TopSpin A/S also as research engineer within silicon based dispensing systems for biotechnology research. In 2006 she joined the Department of Micro and Nanotechnolgy, Technical University of Denmark, where she now are employed as Assistant Professor. Her field of interest is mainly on micromechanical multi-sensors, piezoelectric MEMS devices and encapsulation for harsh environments.

Lars Norgaard received his M.Sc. degree in engineering physics from the Technical University of Denmark (DTU) in 2010, and is now employed at Danfoss A/S as a research engineer within MEMS pressure sensors. His field of interest includes piezo resistive- and capacitive pressure sensors, sensor compensation and calibration methods, and packaging of pressure sensors for harsh environment.

Erik V. Thomsen received his M.Sc. degree in physics from Odense University, Denmark. In 1998 he received his Ph.D. degree in electrical engineering from the Technical University of Denmark. He has been affiliated with the Department for Micro and Nanotechnology, Technical University of Denmark since 1992. In 2008 he became Professor. Since 2003 he has been group leader for the MEMS Applied Sensors group. His current research and teaching interests include MEMS multi-sensors, piezo resistivity of strained layers, piezoelectric MEMS devices, and microsystem packaging. He teaches classes in solid-state electronics, microtechnology, and nanoand microfabrication. 